\title{
Relationship among Personality Type A/B, Locus of Control and Optimism: A Study on Suicide Attempters (20-30 yrs)
}

\author{
Dr. Arvind K Birdie ${ }^{1}$
}

\section{ABSTRACT}

The present study aims to explore the relationship between Personality Type A/B, Locus of control and optimism among suicide attempters. For the purpose of study, a random sample of 35 suicide attempters was taken from Medicine Unit of Sawai Man Singh Hospital, Jaipur. Data were collected by using Gmelch's “Can you type your behavior Scale” and Pareek’s Asufa inventory. Z test, Chi square, percentage and Mean Median and Standard deviation were employed. Results revealed that majority of the suicide attempter's personalities were inclined toward Type A, and has internal locus of control and average optimism. Highly significant correlation was found between type A and locus of control but insignificant with optimism. Significant gender differences were found in males and females on personality type A.

Keywords: Personality Type, Locus of control, Optimism, Suicide Attempters

The world of present century is a chaotic place to live in. Young adults are full of energy and enthusiasm. But they are constantly under pressure to achieve more and more in less time. Suicide among young people has increased dramatically in recent years. In India, three lakh people commit suicide every year. Debt, rejection in love and fear of examinations are the three main reasons why suicide is resorted to (Times of India, News Service, 17 Oct, 2000). Suicidetaking one's own life-is a significant factor in all depressive states. Probably the great majority of people who commit suicide are actually quite ambivalent about taking their own lives. A high proportion of suicide attempter's victims have various associated personality difficulties or disorder (Shkrum\& Johnston,1998). Whenever one talks of the "stress prone individual" one is almost certainly referring to what is called the "Type A personality" (Stress in Work Management). The risk of suicide is about 1 percent during the year in which a depressive episode occurs and it raises to 15 percent over the life time of an individual who has recurrent episodes (Klerman, 1982).Suicide is the ninth leading cause in the United States and third leading cause of death among persons 15-24 years of age.

Krugar,Rober, Caspi, Aushalam, Phil(1996), found that personality traits are differentially linked to mental disorders. The Type A individual is expected to cope with stress in a manner reflective

\footnotetext{
${ }^{1}$ Acting Principal \& Associate Professor, IIMT School of Management (Now Vedatya), Gurgaon (C) 2015 I A Birdie; licensee IJIP. This is an Open Access Research distributed under the terms of the Creative Commons Attribution License (http://creativecommons.org/licenses/by/2.0), which permits unrestricted use, distribution, and reproduction in any Medium, provided the original work is properly cited.
} 


\section{Relationship among Personality Type A/B, Locus of Control and Optimism: A Study on Suicide Attempters (20-30 yrs)}

of the aggressive personality pattern. Locus of control is an important force which affect personality. It is defined as an individual's generalized expectancies regarding the forces that determine rewards and punishments. Individuals with an internal locus of control view events as resulting from their own actions. Persons with an external locus of control view events as being under the control of external factors such as luck(Marsh \& Weary,1995)Presson, Paul and Benarsi (1996) found higher beliefs in a lack of internality are associated with higher levels of depressive symptomatology. Locus of control has been linked with several other variables such as academic achievement health, and psychological adjustment (Haidt\& Rodin,1999)

Seligman defines optimism in terms of how people explain to themselves their success and failures. People who are optimistic see a failure as due to something can be changed so that they can succeed next time around, see a failure as due to something that can be changed so that they can succeed next time around. Lipns, et al.(1993) predicted that optimist would report the likelihood of experiencing more positive and negative events relative to other people. While optimists accept to experience more positive and less negative events, they did not give themselves more favorable predictions compared to other individuals.

Marshall(1992) stressed that optimism and pessimism are differentially linked with fundamental dimensions of mood and personality. Strutton, et al (1992) found that optimism relied more on problem focused coping strategies.

Keeping in mind these important aspects of personality Type, Locus of control and Optimism which are essentially part for individual's behavior and simultaneously an increase in suicide rates all over world, the researcher decided to study this current psychological problem prevalent in youth and its relationship in suicide attempters.

\section{METHOD}

\section{Sample}

The study was being conducted on the reported cases of suicide in the Medicine Unit of SMS Hospital. The data was collected through purposive sampling technique. 35 cases were sorted on the basis of socioeconomic status, education and age (between 20 and 30 years) both males and females.

\begin{tabular}{|l|l|}
\hline Age & $20-30$ yrs \\
\hline SES & Lower middle class \\
\hline Education & Literates \\
\hline
\end{tabular}




\section{Relationship among Personality Type A/B, Locus of Control and Optimism: A Study on Suicide Attempters (20-30 yrs)}

\section{Measures:}

1. Can you Type Your Behavior? The scale given by Gmelch (1982) measures the personality type on the basis of the questionnaire "Can you type your behavior?"The scale consists of 20 items. This scale measure personality on four points along a continuum. Type A and Type B represent extreme positions while Type A2-B2 represent mixed or moderate position.

2. Asufa Inventory The Asufa inventory was used to assess Locus of Control and Optimism. The attribution scale contains 24 pairs of items, comprising of two sets of questions twelve of them pertain to "attribution for success" and twelve to "lack of success”. Each of the four factors (ability, effort, opportunity and luck) has been paired with every other, thus producing six pairs, repeated twice, giving twelve items.

A split- half reliability of 0.56 was found significant at $\mathrm{p}<0.01$ level and for validity, all the variables of ASUFA inventory were compared by UdaiPareek (1954) with scores on Rotters' LOC scale most of the coefficients of correlations with locus of control variables are statistically significant $(\mathrm{p}<0.05)$.

\section{Procedure}

The subjects were administered questionnaire in a comfortable environment after establishing rapport. The help of resident doctors and attendants were taken when patient was unable to understand the language or when they were not in condition of writing or concentrating on the inventory. The inventory in such cases was used as an interview schedule.

\section{RESULTS AND DISCUSSIONS}

Table 1. showed that personality of suicide attempters are mixed that is Type A and B but more inclined towards type A. Locus of control is 1.0200 which shows sample is slightly high in having internal locus of control than external locus of control. The findings goes consonant with the result that as suicide attempters personality is more inclined to type $\mathrm{A}$ and Type A personalities usually are hardworking, competitive, believing in their own capacities which can lead them to have internality disposition. One line of research has stressed on the individual's evaluations of life vents as a critical factor in the stressfulness of that event. Such investigations suggest that it is not the happening of life event per se but rather the person's perception of that event which precepts illness and disorder in personality (Sals and Mullen, 1981).

The optimism level of suicide attempters is average and not high. The finding goes consonant with the following research in past. Suicide is a significant factor in all depressive states and optimism level and hope of depressive people are not high (Sutter, 1976).

Due to average optimism, depression occurs. Depression suicidal impulses may be strongest during early morning hours particularly 5 AM to 7 AM (Hirsh, 1960). 


\section{Relationship among Personality Type A/B, Locus of Control and Optimism: A Study on Suicide Attempters (20-30 yrs)}

The calculated value of X2 comes to be 13.98 when compared with tabulated value of X2 at $1 \mathrm{~d} . \mathrm{f}$ (degree of freedom) and 1\% level of significance which is 6.635 indicates significant relationship between Type A and Internality which is apparent from table 4.1.

\section{Relationship between Type A/Non Type A Personality and Locus of Control Table 4.1}

\begin{tabular}{|l|l|l|}
\hline Personality & External L.O.C & Internal L.O.C \\
\hline Type A & 3 & 11 \\
\hline Non Type A & 17 & 5 \\
\hline
\end{tabular}

This finding goes consonant with the following researches:

Type A persons are overcommitted to their work, often attempt to carry on two activities at once, and believe that to get something done well, they must do it themselves. They cannot abide waiting in lines. Some theorize that the ongoing struggle to achieve in a visible, tangible fashion is driven by an underlying sense of insecurity and low self esteem (Price, 1982; Williams et al., 1992).

When Type A exposed to uncontrollable situations, they showed "helplessness" depression, Type B showed resigned behavior. Type A are more likely to have an internal and Type B an external locus of control (Williams et al., 1988).

Table 4.2 Correlation among various parameters

\begin{tabular}{|l|l|l|l|}
\hline I & II & $\begin{array}{l}\text { Correlation } \\
\text { coefficient }\end{array}$ & P value \\
\hline Type Score & LOC & 0.6553 & $\begin{array}{l}\text { Highly } \\
\text { significant }\end{array}$ \\
\hline Type Score & Optimism & 0.0800 & Non Significant \\
\hline Locus of Control & Optimism & 0.0988 & Non Significant \\
\hline
\end{tabular}

Table 4.2 shows Type score and locus of control to have positive relationship and relationship between Type Score and Optimism is insignificant as optimism is average and dispersed averagely in the sample size that is small. The result are supported by the fact that Type A personalities are not low on optimism but as Type A are more prone towards depression they attempt suicide can be seen in this sample, chances of average optimism is more possible and as studies indicate suicide act is usually a act of moment with Type A personality or mixed type . Relationship between locus of control and optimism is insignificant. This is supported by the various researches which show that internality as well as externality both assess optimism or future events as well as past events in terms of external or internal factors (Simon, 1985). Since 
the optimism level is scattered average among sample so there is no deviation or tilting towards internality and externality.

Table 4.3 Level of Type Score on Males and Females Suicide Attempters

\begin{tabular}{|c|l|l|l|l|l|l|}
\hline Parameter & \multicolumn{1}{|c|}{ Sex } & \multicolumn{1}{|c|}{ N } & \multicolumn{1}{|c|}{ Mean } & \multicolumn{1}{|c|}{ S.D } & Z value & NS/S \\
\hline Type Score & Males & 18 & 14.39 & 2.1 & 2.42 & $0.01 \mathrm{~S}$ \\
\cline { 2 - 7 } & Females & 17 & 12.47 & 2.4 & & \\
\hline
\end{tabular}

Table 4.3 indicates significant relationship between Type A and Gender. The mean type score of males is 14.390 which is very close Type A limit. The differences was found to be statistically highly significant using $\mathrm{Z}$ test at $1 \%$ level of significance. The findings supports the upbringing of males in Indian society where males are more aggressive, competitive, hostile, hard working, impulsive and dominating whereas females are more sympathetic, cooperative and patient. Due to society norms and culture, males are reared and brought up in a manner which fills these traits in them for surviving in the competitive world but for females Indian culture doesn't put so much pressure for these traits and these traits are discouraged and especially when the sample is lower middle class where females are not highly educated.

Table 4.4 Locus of Control in Males and Females Suicide Attempters

\begin{tabular}{|l|l|l|l|l|l|l|}
\hline Parameter & Sex & N & Mean & S.D & Z value & NS/S \\
\hline \multirow{2}{*}{$\begin{array}{l}\text { Locus of } \\
\text { control }\end{array}$} & Males & 18 & 1.040 & 0.127 & 0.76 & NS \\
\cline { 2 - 5 } & Females & 17 & 1.000 & 0.150 & & \\
\hline
\end{tabular}

Table 4.4 indicates the insignificant difference in Locus of Control in males and females which can be attributed to small sample size and conditions in form of external and internal factors same for both sexes. Extremely external or internal is not quite possible for a personality. Both work simultaneously. In different condition, one emerges as strong. But internality can be perceived as related to either the stable (ability) or variable factor (effort). Similarly externality can be perceived as related to the stable factor (task difficulty or opportunity) or the variable factor (luck or chance) (Weiner,1974.)

Table 4.5 Optimism in Males and Females Suicide Attempters

\begin{tabular}{|l|l|l|l|l|l|l|}
\hline Parameter & Sex & $\mathbf{N}$ & Mean & S.D & Z value & NS/S \\
\hline \multirow{2}{*}{ Optimism } & Males & 18 & 47.940 & 3.316 & 0.09 & NS \\
\cline { 2 - 5 } & Females & 17 & 48.060 & 3.896 & & \\
\hline
\end{tabular}




\section{Relationship among Personality Type A/B, Locus of Control and Optimism: A Study on Suicide Attempters (20-30 yrs)}

Table 4.5 indicates very low optimism level difference in males and females and has no significant difference between males and females on the optimism level. Eminent sociologist Dr. Ram Ahuja said that women, nowadays were imbibing modern values and wanted a place for themselves in the family and the society while in return, they are not allowed to do so" This conflict drives many to suicide(Hindustan Times, Jan7,2001)

\section{CONCLUSION AND IMPLICATIONS:}

Definitely this study provides valuable information to the society. People at risk can be identified and helped. Causes that force people towards death can be found and family members and society can help in eradicating them. Due to increased rate in suicide, guidance and counseling centers can be opened at several levels to help the vulnerable people. By this research more new dimensions, aspects, conclusions; fields can be drawn in Human Behavior sciences and psychopathology.

\section{REFERENCES}

Agrawal, A. (1974) : A Study of Locus of Control and Self-Concept ofFront Benches and Back Benches, MANAS, 4(2), 1-7.

Ahuja, R. (1992) 1 Social Problems' in India, Nice Printing Press, New Delhi, 165-180.

Barone, Byrne, Kantowitg (1980) : Understanding Behaviour, Holt, Rinehart and Winston, Toronto, New York, Chicago, 531-535.

Bigner. (1970) 1 Psychology of Personality, Mettven and company Ltd. London. pp 139-152.

Blumenthal, Susan and Kupfer, D. (1990): Suicide Across The Life Cycle, American Psychiatric

Carson, Rgbert C. and Bukher, James N. (1992):Abnormal Psychology and Modern Life, Duke, University , University of Minnesota, Haoper Collins Publishers, 410-425,

Deauc, K. (1977) : Attributing Causes for one's own performance; the effect of sex, norms and outcomes, Journal of Research in Personality, 11, 59-72.

Goleman, D. (1995) : Emotional Intelligence, Bantam Books, Publishing History, New York.

Goleman, D. (1998) : Working with Emotional Intelligence, Bantarn Books, New York.

Goode, E. (1990): Deviant Behaviour, Prentice Hall, New Jersey,6-7, 27.

Haney, Thomas L., Maynard, Kimberley E., Stephen, J. Scherwitz, L.W. et al.(1996) : Interpersonal Hostility Assessment Technique: Description 85Validation against the criterion of coronary artery disease, Journal of Personality Assessment, 66(2), 386-401.

Heaven, Patrick C.L. (1996) : Personality ai Individual differences American Journal of Psychology, 20, 47-54.

Hewett, J.H. (1980) : After Suicide, Westminster Press, Philadelphia, Pennsylvania, 513-514.

Hurlock, E.B. (1978) : Child Development, (sixth edition), McGraw-Hill Publishers, Aukland.

Hurlock, E.B. (1992) : Personality Development, Tata McGraw Hill Publishing Company Ltd., New Delhi, 394-396.

Hyde, Margret 0. and Elizabeth, H.F. (1987): Suicide: The Wilden Epidemic, Franklin Watts, New York, 866-900. 


\section{Relationship among Personality Type A/B, Locus of Control and Optimism: A Study on Suicide Attempters (20-30 yrs)}

Kalgsbrun Francine (1984) : Too Young To Die: Youth and Suicide, Pocket Books, New York, 116-117.

Khel-man, Ge;-lahld L. (1986): Suicide and Depression Among Adolescents and Young Adults, American Psychiatric Press, Inc. Washington D.C., 198-200.

Krnegef, R.F., Caspi, A. Moffitt, Tgrrie E. et al.(1996) : Personality traits are differentially linked to mentaldisorders: A multitrait-multidiagnosisstudy of an adolescent birth cohort, Journal of Abnormal Psychology,1O5(3), 299-312.

Lamude, Kevin G., Furno-Lamude, Diane \& Lichtenslein, A.(1995): Compliance-gaining tactics of locus of control-scoring T.V. viewers, Psychological Reports, 76(2), 458.

Landau, Ruth (1995) : Locus of control and socioeconomic status: Does internal locus of control reflect real resources and opportunities or personal coping abilities? Social Science \& Medicine, 4l(11), 1499-1505.

Leftrourt. (1976) : Locus of Control Lawarence, Associates Publishers, Hillsdale, pp 58-60.

Lester David (1995):An examination of Leena, Theory of Suicide, Perceptual \& Motor Skills, $30(2), 578$.

Lester, Davide and Nafarajan, Mangai (1995) :Predicting the time series suicide and Murder rates in India, Perceptual and Motor Skills,80(2), 570.

Luzzo, D.A. and Ward, B.E. (1995) :The relative contributions of self efficiency and locus of control tothe prediction of vocational congruence, Journal of Career development, 21(4), 307-317.

Madison, Arnold (1981) 1 Suicide and Young People, Clarion/Houghton Mifflin, Boston, 200208.

Mark, John E. and Holly, Hiekler v. (1982) The Life and Suicide of an Adolescent Girl, NAI Books, New York, 502-506.

McCollum, Bruce and Lester, David (1995) :Authoritarianism, Antiauthoritarianism and Locus of Control, Psychological Reports, 76(2),418.

Musen, P.M., Conger, J.J., Kagan J- (1979) : Child Development and Personality (sixth edition), Harper, 85 Row Publishers, New York.

Nathawat and Joshi, Uma (1997) :The effect of Hardiness and Type A behaviour on the perception ofLife Events and their Relationship to Psychological Well Being, Indian Journal of Clinical Psychology, 24(1),52-57.

Nielsen, L. (1987) : Adolescent Psychology: A Contemporary View, Hilt, Rinehart and Winton Inc, New Delhi, Chicago, Tokyo, 683-690.

Papallia, Diane E. and Olds, Sally W. (1992) :Human Development, University of Texas, Tata McGraw Hill Publishing Company, New Delhi, Fifth Edition,546-550.

Patrika Delhi Bureau: Mansik Avsaad Se Aatmahataon Mein Bhadhotri, Dec 30, 2000.

Peez, G., Anna, M. and Sanjnan, P. (1996): Type A behavior patterns (global and main components) attention performance, cardiovascular reactivity and causal attributions in the presence of different levels of interference, Personality and Individual Differences, 20(1), 81-93. 


\section{Relationship among Personality Type A/B, Locus of Control and Optimism: A Study on Suicide Attempters (20-30 yrs)}

Press, Inc., Washing D.C., 110-111.

Presson, Paul K. and Benassi, V. A. (1996) : Locus of Control orientation and depressive symptomatology: A metal analysis, Journal of Social Behaviour and Personality, 11(1), 201-212.

Rajasthan Patrika: Jaipur Main CellphoseKhaane Se HarTeesre Din Maut, Jan. 7, 2001.

Rao, C.S.: Delusions of love push up suicide rate, Times of India, Oct. 17, 2000.

Rawdan, Vicki A., Willis, Frank N. and Ficken (1993): Locus of Control in young adult in Russia and the United States, Perceptual \& MotorSkills, 80(2), 599-604.

Read, Stephen J. and Stephen, Walter, G. (1979) :Personality Social Psychology Bulletin, 5(2), 196-200.

Rosen, Gregory (1965) : Abnormal Psychology, University of Minnesota, WB. Saunders Company, Philadelphia and London, 554.

Rothrum, B., Marry, J., Walker, Janis Updike and Ferns, W.(1996) : Suicide behaviour amongmiddle class adolescents who seekcrisis services, Journal of Clinical Psychology, 52(2), 137-143.

Roy, Alec (1986): Suicide, Williams and Wilkins, Baltimore, Maryland, 8-10.

SadanandanUnni, Annie, J. Mani (1996) : Suicidal ideators in the psychiatric facility of a general hospital-A psycho demographic profile, Indian Journal of Psychiatry, 246 (3), 79-86.

Saloff, P.H., Lis, J.A., Kelly, T., Cornellins, J. and Urich, R. (1994) I Risk Factors for Suicidal Behaviour in Borderline Personality Disorder, University of Pittsburgh, AMJ Psychiatry Press, Inc., 8, 20, 96.

Schutte, James W., Valerio, John K. and Carrillo, V. (1996): Optimism and Socioeconomic Status: A Cross cultural study, Journal of Social Behaviour and Personality, (11(1), 201212.

Seligman, M. (1994): The Realms of Life Optimism and Learned Helplessness, 116-134.

Sibilia, Lucio, Picszzi, Roherts and Nardi, A.M. (1995): Identifying a psychological profile of Type a behaviour pattern, Stress Medicine, 11(4), 263-270.

Singh, D.K.: Housewives more prone to suicide, Hindustan Times, Jan. 7, 2001.

Smith. T. N. and Rhodewalt, F. (1986): On States, traits and processes: A transactional alternative to the individual difference assumptions in Type $\mathrm{A}$ behaviour and Physiological reactivity. J. Res Pers., 20, 259.

Steiner. (1997) : Achieving Emotional literacy. Avon Books, Newyourkpp 29-30.

Sul, J. and Sanders, G.S. (1988) : Why to some Behavioural StylesPlace People at Coronary Risk? Hills Dale, NJ, Eribaum.

Telsten, Gary and Leithen, Christopher L. (1996) :Gender of Opponent and TYPC A competitiveness Predict cardiovascular responses during competition, Journal of Social Behaviour and Personality, 11(1), 79-86.

Thankachan, M.V. and Mishra, H. (1996): Type A personality among Duodenal Ulcer Patients, Indian Journal of Clinical Psychology,23(1), 16-20.

Tiger, L. (1995) : Optimism: The Biology of Hope, Kodansha, N .Y_ 


\section{Relationship among Personality Type A/B, Locus of Control and Optimism: A Study on Suicide Attempters (20-30 yrs)}

Trend well, P. (1988) 1 The Problem of Adolescence, Richard Clay Ltd., Bungay, 52, 230

Walk, Ducette. (1973) : The modulating effect of locus of control in relation to achievement, Journal of personality Vol 15(2) pp. 59-60

Yadav, Suman, Nathawat (2000) :A Study of Executives under Stress: Hardiness Type A/ BBehaviour and Coping as predictors of Organizational Role Stress and Job Anxiety (Ph.D. Thesis), Unpublished Work under Rajasthan University.

Zirnbardg, phillip G_ (1935) ; Psychology and Life, Scott, Foresman \& company, London, 12” Edition’ 538-39.

\section{Webs}

www.befrienders.org/infor/statistics/htm.

www.geocities.com/cazie/index27.html.

www.muohio.edu/npsyhersite/control/overview.htx.

www.nami.org/helpline/suicide.htm.

www.nimh.nih.gov/research/suifact.htm.

www.tms.com.av/tms10z.html.

www.workhealth.org/rish/rfblocus.html.

www.workshrink.com/archive.html. 